\title{
FORMAÇÃO CONTÍNUA DE PROFESSORES DE INGLÊS NA CIDADE DE VITÓRIA, ES
}

\author{
Christine Sant'Anna de ALMEIDA \\ Universidade Federal da Bahia
}

RESUMO: Este artigo reporta um estudo de caso que teve como objetivo identificar as necessidades formativas dos professores de Língua Inglesa em exercício na rede municipal pública de ensino de Vitória, ES. O propósito do estudo foi examinar em que medida o processo formativo oferecido por essa instituição empregadora atendia às necessidades dos docentes. Para tanto, foi conduzida uma análise de necessidades com esses professores, fazendo uso de questionário com os docentes. A Prefeitura Municipal de Vitória também foi ouvida por meio de realização de entrevistas com os gestores do processo formativo. Os resultados revelaram que o processo formativo oferecido não atendia às necessidades dos professores. Tal resultado motivou a elaboração, a título de ilustração, de um roteiro sugestivo de ações formativas. Tal roteiro atende às exigências e preceitos de documentos diretivos e vai ao encontro do que os estudiosos da área sugerem como desejável para a formação contínua de professores de Língua Inglesa e das necessidades manifestadas pelos professores pesquisados. O roteiro sugestivo foi elaborado em forma de uma proposta curricular com descrição detalhada dos encontros a serem realizados em um ano letivo, contemplando assim as necessidades apontadas pelo grupo de docentes participante e opções de tentativas de soluções para as demandas apontadas.

PALAVRAS-CHAVE: formação contínua de professores de inglês; análise de necessidades; professores de inglês de escola pública

ABSTRACT: This paper reports a case study that aimed to identify the education needs of the English teachers in the municipal public education system in Vitoria, ES. The purpose of the study was to examine to what extent the continuing education process offered by this employer institution met the needs of the teachers. In order to do this, a needs analysis was conducted with these teachers through the use of questionnaires. The Municipal Education Secretary from the City Hall of Vitória was also heard through interviews with its managers. The results revealed that the continuing education process offered did not meet the teachers' needs. This result motivated the elaboration, by way of illustration, of a suggestive script of in-service education activities. This script meets the requirements and precepts of directive documents and meets what scholars in the area suggest as desirable for the continuing education of English language teachers and the needs expressed by the researched teachers. The suggestive script was elaborated in the form of a curricular proposal with detailed description of the meetings to be held in a school year, contemplating the needs pointed out by the participating teachers and options of attempts to solve the mentioned demands.

KEYWORDS: continuing education of English teachers; needs analysis; English teachers from public schools

A Prefeitura Municipal de Vitória, PMV, por força de sua Política de Formação Continuada para os Profissionais da Educação do Sistema de Ensino de Vitória (VITÓRIA, 2007), se compromete a oferecer educação contínua ${ }^{1}$ a seus servidores. O documento apresenta uma

\footnotetext{
${ }^{1}$ Acompanho Oliveira (2010), ao adotar a terminologia educação/formação contínua, em vez de continuada, ao me referir à continuidade de estudos de um profissional. Isso porque entendo que ambos os termos são idênticos morfologicamente, pois são adjetivos. No entanto, semanticamente, o termo continuada traz consigo uma implicação de uma ação com início e fim, ao contrário de contínua, que carrega em si a ideia de um progresso
} 
proposta de formação para os profissionais da Educação no município, entendendo que "a formação deve mobilizar os saberes e os fazeres dos profissionais da educação e ser constituída de forma colaborativa com esses sujeitos" (VITÓRIA, 2007, p. 4, grifo meu), visando alcançar o "empoderamento ${ }^{2}$ desses sujeitos na ação político-pedagógica em seus contextos de atuação" (VITÓRIA, 2007, p.11).

As práticas formativas oferecidas pela Secretaria Municipal de Educação, SEME, são coordenadas pela Gerência de Formação e Desenvolvimento da Educação, GFDE, e se incumbe das seguintes responsabilidades no processo de oferta de formação contínua dentro da SEME: elucidar as pessoas envolvidas nas formações por área de conhecimento quanto à política de formação da SEME e quanto à escolha do coordenador do grupo, fomentar reuniões periódicas com o coordenador da área, bem como apreciar os relatórios referentes aos encontros por ele redigidos, a fim de promover alterações necessárias para que "os princípios da formação ${ }^{3}$ sejam assegurados" (VITÓRIA, 2007, p. 15). É responsabilidade do coordenador do grupo de professores de cada área de conhecimento, providenciar a organização dos encontros de formação, registrar por escrito cada um deles, encaminhar demandas que surgirem durante esses encontros, bem como reunir-se com a gerência da GFDE para, conjuntamente, avaliarem o processo de formação. São várias as ações formativas realizadas, dentre as quais a realização de seminários sobre práticas pedagógicas, a formação por área de conhecimento com os professores das séries finais - que no caso da Língua Inglesa são os mesmos professores das séries iniciais do Ensino Fundamental, EF -, a formação com os coordenadores de turno e a formação dos pedagogos (VITÓRIA, 2012).

Fiz parte dessa rede de ensino, como professora de língua inglesa, por quatro anos, de 2007 a 2011, e ativamente participei dos encontros, denominados Formação. Nesses momentos formativos pude vivenciar uma certa insatisfação dos colegas docentes com os encontros que lhes eram proporcionados ${ }^{4}$. A partir dessa constatação, nasceu a motivação de cientificamente verificar em que medida as Formações oferecidas atendiam as necessidades dos docentes de língua inglesa que estavam, à época da coleta de dados, 2012, efetivamente em exercício.

Participaram do estudo 86 pessoas - 83 professores e três gestores. O número total de professores em exercício em 2012, época da coleta de dados, girava em torno de 100-105 5 . Foram distribuídos 101 questionários aos professores que estavam efetivamente em exercício, não levando em conta se eram efetivos ou temporários na rede de ensino. De qualquer sorte, acredito que tendo a contribuição de $82 \%$ de toda a população docente que eu poderia alcançar,

constante - o que vem a ser mais apropriado ao objetivo deste trabalho. Ressalto ainda que, em citações diretas, respeito e reproduzo o termo continuada como apresentado por teóricos ou documentos nesta pesquisa elencados.

${ }^{2}$ Entende o documento Política de Formação Continuada para os Profissionais da Educação do Sistema Municipal de Ensino (VITÓRIA, 2007) ser o empoderamento "promovido por processos formativos que fortalecem as capacidades dos sujeitos, individuais ou coletivos, em todas as instâncias para a tomada de decisões" (VITÓRIA, 2007, p. 11).

3 São os princípios da formação estabelecidos na Política de Formação Continuada para os Profissionais da Educação do Sistema Municipal de Vitória: trabalho coletivo, compromisso com práticas emancipatórias e inclusivas, valorização da postura do professor como pesquisador de sua própria prática (VITÓRIA, 2007).

${ }^{4}$ Este texto é derivado da tese de doutorado de minha autoria intitulada "A formação contínua de professores de língua inglesa da rede municipal pública de ensino de Vitória, ES, à luz da análise de necessidades", defendida na PUC-SP em dezembro/2014.

\footnotetext{
${ }^{5}$ Não foi possível indicar precisamente o quantitativo pois a SEME não me permitiu acesso a qualquer de suas listas de controle dos docentes de Língua Inglesa em exercício, o que me fez visitar cada uma das 46 escolas de Ensino Fundamental, EMEFs, que atendiam o Ensino Fundamental II, do $6^{\circ}$ ao $9^{\circ}$ ano - séries em que o ensino de Língua Inglesa era obrigatório na rede de ensino.
} 
aos dados levantados podem ser atribuídos validade e confiabilidade. Três gestores participaram do estudo por meio de entrevistas semiestruturadas, sendo que um desses gestores, o coordenador do grupo de Inglês, também participou na qualidade de professor em exercício.

Os três gestores participantes são vinculados à PMV por serem professores da Educação Básica no Ensino Fundamental, EF, e ocupavam, em 2012, posições de gestão: o gerente da GFDE, que há três anos ocupava o cargo; uma técnica pedagógica da GFDE, na gerência desde 2011; e o coordenador do grupo de Inglês, professor da rede há cinco anos e há dois ocupava esta posição de fazer a ponte entre os professores de Língua Inglesa e a GFDE.

O quadro docente participante do estudo contava com 62 pessoas do sexo feminino e 21 do masculino, sendo que 64\% deles possuía entre 30 e 49 anos de idade. $82 \%$ dos participantes, 68 professores, são professores efetivos estáveis ${ }^{6}$ que possui experiência que varia entre a completude do Estágio Probatório, que é de três anos, até a experiência de dez anos como docente da rede na rede - fato que leva a acreditar que as opiniões colhidas serão representativas das necessidades pelo grupo apontadas. Todos os 83 participantes têm licenciatura em Língua Inglesa, 67 informaram ter concluído cursos de especialização ${ }^{7}$ e cinco a conclusão de mestrado. 51 dos 83 professores trabalham com ensino de Inglês em outros ambientes escolares que não a PMV, sendo a maioria em escolas do EF e Médio. Na PMV, os professores atendem a diferentes públicos: EF I, EF II e EJA, e o EF II é o segmento que mais demanda professores, em função do número de alunos e a quantidade de horas-aula da disciplina nas séries que compõem o EF II. 78 dos 83 professores participantes informaram nos questionários respondidos que se mantêm atualizados com assuntos de sua área de atuação por meio principalmente de cursos, congressos, seminários, formações oferecidas pelo sistema de ensino ao qual pertencem, treinamentos diversos, leituras, atividades desenvolvidas via internet e por meio de troca de experiências com colegas da área.

No questionário aplicado aos professores, duas perguntas eram diretamente ligadas à qualidade da Formação oferecida pela SEME/PMV:

1) Qual é sua opinião sobre a Formação Continuada oferecida pela PMV? Por quê?

2) Na sua opinião, como a Formação Continuada da PMV pode contribuir para tratar das questões relacionadas ao ensino-aprendizagem de inglês na sala de aula?

Em resposta à primeira pergunta, dos 83 professores questionados, $70(84,3 \%)$ expressaram sua opinião, 4 não responderam, 6 informaram que não iriam opinar porque nunca haviam participado de tais encontros e 3 informaram não ter opinião estabelecida sobre as Formações. As respostas a tal questionamento foram classificadas em duas categorias opostas: opinião favorável e opinião desfavorável. A questão, que oferecia a possibilidade de múltiplas opiniões, resultou em 139 menções. Delas, 111 (80\%) se encaixam na categoria opinião desfavorável e $28(20 \%)$ se encaixam na categoria opinião favorável. Os números demonstram uma insatisfação do professorado com a qualidade ou com a logística das Formações promovidas pela GFDE da SEME/PMV.

55 opiniões desfavoráveis apontam para a necessidade de as Formações serem mais específicas e mais objetivas para a área do ensino de Inglês. Esses números corroboram o estudo de Santana (2010), que afirma que os professores valorizam as formações que privilegiam a prática e que a presença desse quesito atribui validade à formação. Ainda na categoria opinião desfavorável,

\footnotetext{
${ }^{6} \mathrm{O}$ termo professor efetivo estável refere-se ao docente que é concursado na instituição, já cumpriu seu Estágio Probatório (VITÓRIA, 2008), foi satisfatoriamente avaliado por seus gestores e desfruta da estabilidade real de seu cargo.
}

\footnotetext{
${ }^{7}$ A maioria dos cursos informados é da área de Educação e/ou Ensino.
} 
os professores elencaram: falta de praticidade das reuniões; ausência de especialistas e/ou estudiosos da área do ensino de línguas estrangeiras no comando dos encontros; não uso da língua inglesa nas Formações; comprometimento do tempo destinado ao planejamento semanal, produção e correção de atividades, confecção de avaliações e atualização de pautas; isolamento dos professores da EJA; e espaço formativo transformado em espaço de reclamação.

Apesar de a maioria dos respondentes ter apontado aspectos negativos em relação à Formação que é oferecida pela PMV, 28 registros de opiniões favoráveis foram feitos: 24 professores afirmam que é boa a qualidade da Formação que a instituição empregadora proporciona, 3 professores relevam a boa intenção por parte da PMV de abrir esse espaço de compartilhamento de conhecimentos e experiências de seus docentes e 1 professor solicita que os encontros de Formação não deixem de existir. A partir das informações coletadas, é possível afirmar que, para o corpo docente investigado, os motivos que fazem o processo formativo ser significativo, e por isso desejado, são pertinentes às categorias apresentadas por Galindo e Inforsato (2008) como os motivos que levam o professorado a tomar parte em ações formativas, tais como: aquisição de novos conhecimentos, pertinência dos temas, aplicabilidade da formação, troca de experiências com colegas e melhoria em suas aulas.

Em relação à segunda pergunta, Na sua opinião, como a Formação Continuada da PMV pode contribuir para tratar das questões relacionadas ao ensino-aprendizagem de inglês na sala de aula?, dos 83 professores questionados, $72(86,7 \%)$ expressaram sua opinião e 11 não responderam. 69 docentes afirmaram que as Formações oportunizam a abordagem de questões relacionadas ao ensino-aprendizagem de Inglês nas salas de aula de suas escolas, e 3 docentes afirmaram não saber se as Formações poderiam contribuir com tais questões.

As respostas afirmativas dos docentes apontam para as seguintes contribuições: incentivo à troca de experiências entre os professores de Inglês; abordagem de aspectos mais precisos, específicos, para o ensino-aprendizagem da língua em questão; oferta de oficinas e/ou cursos com pesquisadores da área; trabalho voltado para a disciplina e para a melhor interação entre os discentes; e valorização do professor, começando por ouvi-los mais. Os desejos manifestados pelos professores, ao privilegiarem aspectos práticos, remetem ao estudo de Rodrigues e Esteves (1993, p. 85) que, ao discorrer sobre as necessidades dos professores participantes, constata um "predomínio nítido das referências à transmissão/avaliação de conhecimentos, à preparação das aulas e à sua execução".

Os professores participantes também foram questionados acerca de suas necessidades no seu exercício profissional, ou seja, àquilo que ele manifesta ser uma lacuna e que compromete o seu fazer docente. Como dito por Rodrigues e Esteves (1993, p. 79), "a determinação de necessidades de formação é um processo complexo que exige múltiplas abordagens complementares". Por isso, não almejei abranger a totalidade da problemática das carências ${ }^{8}$ que os professores sentem, mas sim tento perspectivar uma aproximação com as necessidades que esses sujeitos participantes do estudo informam ter.

O questionário aplicado aos docentes participantes também contemplou questões referentes as vontades, aspirações, desejos e expectativas que os professores de Língua Inglesa em efetivo exercício na rede municipal de ensino de Vitória têm em relação ao processo formativo oferecido pela PMV. As questões do questionário versaram quanto à proficiência linguística, aos desejos quanto à qualidade da Formação e aos desejos quanto a assuntos a serem contemplados na Formação.

\footnotetext{
${ }^{8}$ Os termos necessidade, carência e falta são aqui entendidos como sinônimos.
} 
Os gestores responsáveis pelo oferecimento desses processos formativos, durante as entrevistas com eles realizadas, afirmaram que sua meta é a qualificação do trabalho docente com vistas à aprendizagem do aluno. No entendimento da GFDE, os momentos de Formação devem constituir para os docentes, oportunidades de contato, desenvolvimento, conhecimento, discussão, reflexão e construção de práticas ou questões que perpassam a escola e que não fizeram parte da formação inicial desses profissionais. Ainda, segundo o Gerente entrevistado, a GFDE imagina que os encontros formativos organizados pela PMV aos seus docentes atuam como provocadores de reflexão nos professores acerca do resultado que se tem nas salas de aula ser também produto da atuação do professor em suas salas.

Apreende-se, a partir dessas considerações, que é expectativa da equipe gestora da Formação que os docentes da rede de ensino discutam e estejam envolvidos em assuntos de cunho não só pertinente a suas áreas de conhecimento, mas também em assuntos que pertençam a um escopo de maior amplitude no cenário escolar.

Pelo acima exposto, é possível inferir que a atual Política de Formação da Secretaria não é claramente explicada aos docentes, pois, em nenhum momento, os professores se manifestaram conhecedores da abrangência de tal visão. Isso porque os discursos dos docentes muito frequentemente aparecem na forma de reivindicação de encontros formativos que contemplem especificidades para o ensino de Língua Inglesa.

Os encontros de Formação são planejados em reuniões do coordenador com a equipe GFDE e outros setores da SEME para definição da linha de trabalho e da logística de organização dos encontros. Os temas contemplados nos encontros formativos oferecidos pela PMV são selecionados à luz de discussões realizadas pela equipe de formação, levando em consideração as indicações de professores, as demandas da época e também a linha ideológica da administração em vigor. Nessas reuniões da equipe de formação, há sugestões de nomes de palestrantes que, em geral, são profissionais reconhecidos por atuarem e/ou pesquisarem o tema escolhido ou com titulação e trabalhos na área. Não é um requisito que o palestrante tenha conhecimento da realidade da escola pública, mas é desejável.

Não obstante, conforme declarações dos participantes, é justamente a falta desta ligação entre os temas apresentados e a realidade cotidiana dos professores participantes que muitas vezes levam esses docentes a não se interessarem pela Formação da PMV. Dados oferecidos pelos professores participantes expressam o não atendimento das demandas do docente, fato que encontra respaldo nas afirmações de Galindo e Inforsato (2008) que, ao elencarem categorias que desmotivam os docentes a participarem de experiências formativas, apontam razões como: propostas ineficazes, carência de propostas, separação entre teoria e prática e desinteresse do professor. Logo, faz-se imprescindível que as demandas do professor e sua realidade educacional sejam atendidas, bem como sejam consideradas suas concepções sobre sua prática docente, pois tais fatores são determinantes no engajamento dos professores em seus processos formativos (SANTANA, 2010). A Gerência ressalta ainda que ao final de cada ano letivo, os professores participantes das Formações avaliam os encontros que tiveram e indicam assuntos que gostariam que fossem abordados no futuro. Não existe o impedimento de que professores participantes, ao longo de um ano letivo, solicitem ou indiquem temáticas para serem incluídas, na medida do possível, na agenda formativa.

Em linhas gerais, é explicitado pela GFDE que a avaliação que faz do processo formativo que oferecem é positiva. Todavia, a GFDE não explicita para os professores o que entende por essa boa Formação e o que ela deve contemplar. Tal desconhecimento por parte dos professores acerca de questões como pertinência, adequabilidade, relevância, aplicabilidade e conveniência do conteúdo dos encontros formativos provoca um estado de insatisfação deles. Eventualmente, 
isso pode comprometer o aproveitamento desses docentes no processo formativo e, consequentemente, no exercício de sua atividade profissional. Assim, firmo-me na visão de Villani (2010, p. 88) acerca do processo de formação contínua dos educadores da rede pública municipal, ao notar que também aqui em Vitória, essa educação continua "na contramão não só da acelerada globalização do mundo atual, mas também, das próprias leis federais deste país", pois não consegue proporcionar a seus docentes o apoio e o respaldo, tanto estrutural, técnico ou pedagógico, indispensáveis para uma atuação didática de qualidade.

Dessa maneira, volto a evidenciar a falta de alinhamento das visões dos professores e dos gestores do processo formativo sobre o propósito da Formação. A interpretação dos dados da pesquisa mostrou que os professores se manifestaram insatisfeitos em relação à Formação oferecida, alegando que ela não atende a suas necessidades e desejos. Em contrapartida, a GFDE considera que oferece uma boa Formação.

O processo formativo, entendido como um todo coerente, deve atender a exigências do funcionamento das organizações, a interesses sociais presentes na situação de trabalho e a expectativas dos indivíduos (RODRIGUES; ESTEVES, 1993). Quando essa integralidade não se faz presente, surgem lacunas que comprometem aquilo ao que o processo se destina; no caso deste trabalho, a qualidade do ensino de Língua Inglesa na PMV. Nessa perspectiva, entendo que o ensino de Língua Inglesa na PMV está comprometido, pois a visão do processo formativo não constitui um todo coerente, fragmenta-se entre a gestão e os professores. A gestão da GFDE entende que a política de formação deva promover reflexões que abarquem uma dimensão mais abrangente da realidade escolar, não apenas em assuntos pertinentes às áreas de conhecimentos específicos. Tal visão também contempla ações que buscam ir ao encontro daquilo que é sinalizado pelos professores. Contudo, a gestão ainda afirma que os professores desta rede de ensino anseiam por processos operacionalizáveis, ou seja, passíveis de serem aplicados em sala de aula em um curto espaço de tempo, e conteúdos que não podem ser objetivamente transpostos para a realidade da sala de aula são usualmente refutados. Os professores, por sua vez, reivindicam, prioritariamente, a especificidade de assuntos referentes ao ensino da língua estrangeira como componente de seu processo formativo.

Concordo com Kumaravadivelu (2011, p. x) que o processo formativo de professores de línguas precisa ser suficiente "para enfrentar os desafios postos pela acelerada globalização econômica, cultural e educacional" da hodierna sociedade. Portanto, ao elaborar o roteiro sugestivo de ações formativas para os professores de Inglês da PMV, considerei, além dos resultados da análise de necessidades realizada com os professores e as diretrizes federais e municipais que orientam o sistema educacional, a "complexidade educacional que se tornou a marca de nossa sociedade global de conhecimento" (KUMARAVADIVELU, 2011, p. 17).

Nessa perspectiva, a ideação deste trabalho, ou seja, a ideia de ação advinda dos resultados, foi elaborar um roteiro sugestivo para encontros formativos a serem oferecidos pela PMV. O roteiro sugestivo, conforme o próprio nome denota, não tem natureza normativa ou prescritiva. Sua elaboração parte do pressuposto que os gestores e os professores da PMV, embora não compartilhem da mesma visão em alguns aspectos, são comparticipantes de um mesmo objetivo: a qualidade do ensino de Língua Inglesa na PMV. Por isso, aproximar suas visões favorece que esse objetivo seja alcançado de forma bem sucedida. Seu objetivo é servir de referencial para consulta e orientação, constituindo um banco de ideias.

A construção do roteiro teve como base as informações colhidas dos professores, em especial no tocante a suas necessidades formativas e desejos que nutrem em relação ao processo formativo que recebem da SEME/PMV. Optei por fundamentá-lo em duas linhas de ação: (i) aperfeiçoamento linguístico e (ii) aperfeiçoamento didático-pedagógico. Juntas, essas duas 
linhas de ação visam abarcar as necessidades e os desejos formativos dos professores de Língua Inglesa discutidos ao longo desta tese. A linha de ação aperfeiçoamento linguístico foi concebida a partir de sugestões de alternativas para a prática do idioma por parte do professor. A linha de ação aperfeiçoamento didático-pedagógico foi concebida a partir da possibilidade de acontecerem, durante um ano letivo, oito encontros formativos por área de conhecimento.

(i) A linha de ação aperfeiçoamento linguístico:

A prática da língua estrangeira é um desejo de $86,7 \%$ dos professores ( 72 dos 83 participantes). Os docentes alegam, principalmente, que não têm oportunidade de praticar o idioma estrangeiro também por lidarem com alunos que possuem nível básico de conhecimento desse idioma. Tal circunstância, afirmam, leva-os à falta de fluência e proficiência. O expressivo quantitativo de professores que manifestou o desejo de praticar a língua estrangeira demandou que, na elaboração do roteiro sugestivo de ações formativas para os professores de Inglês, esse aspecto fosse contemplado. Assim, este roteiro sugestivo pressupõe que a língua estrangeira seja prioritariamente utilizada como veículo de comunicação em todas as oportunidades de encontro dos docentes. Contudo, conhecendo o contexto dos encontros de formação e, por isso, presumindo a existência de dificuldades de se promoverem encontros em língua inglesa por questões de ordem organizacional, logística ou relacionadas a aspectos quanto à proficiência do professor, tive a necessidade de pensar em alternativas para lidar com essas eventuais dificuldades.

Assim, este roteiro sugestivo aponta duas alternativas: o uso da língua inglesa, em suas diferentes habilidades, como veículo de comunicação nas ações formativas da linha de ação aperfeiçoamento didático-pedagógico, de forma a contemplar a linha de ação aperfeiçoamento linguístico; e o incentivo ao aprimoramento linguístico dos docentes por meio de ações promovidas pela PMV.

A primeira alternativa, o aprimoramento linguístico dos docentes como veículo de comunicação nas ações formativas da linha de ação aperfeiçoamento didático-pedagógico, está suposta para acontecer da seguinte maneira: adoção da língua inglesa no desenrolar dessas ações, bem como nos possíveis desdobramentos delas. Desse modo, os participantes terão a oportunidade de exercer a prática desse idioma mais constantemente. Algumas situações previstas são:

- emprego da língua inglesa como meio utilizado na comunicação oral e escrita durante as ações formativas;

- utilização de textos em inglês como base de discussão das temáticas exploradas;

- uso de excertos áudio ou videogravados em língua inglesa explicativos ou ilustrativos de assuntos pertinentes à temática da ação formativa;

- visita e navegação em sítios eletrônicos em língua inglesa para consultas, pesquisas, cursos on-line, produção de materiais ou contatos profissionais e sociais;

- compartilhamento de experiências durante e após as ações formativas;

- postagem de relatos, de tarefas realizadas ou de sugestões de atividades.

A segunda alternativa para lidar com a dificuldade de se promoverem encontros em língua inglesa supõe o oferecimento de sugestões para o incentivo ao aprimoramento linguístico dos docentes por meio de ações promovidas pela PMV. São elas:

- parceria com curso de idiomas, oportunizando aos professores espaços dessa natureza possibilita a prática do idioma estrangeiro e, consequentemente, aperfeiçoamento e proficiência;

- parceria com o departamento que abriga o curso de Letras/Inglês de instituições superiores de ensino, visando uma parceria com professores-pesquisadores, o que pode favorecer a criação de projetos de extensão que ofereçam oficinas e oportunidades para 
os docentes da rede municipal de ensino desenvolverem e aprimorarem suas habilidades linguísticas e pedagógicas;

- parceria com entidades que promovem eventos direcionados a professores dessa língua;

- criação de um canal de comunicação entre seus docentes e entidades promotoras de eventos, como a Embaixada Americana e o Conselho Britânico, para a divulgação de oportunidades de estudo no exterior, conferências ou chats em inglês;

- disponibilização de calendário com informações de eventos formativos diversos na área de ensino-aprendizagem de Língua Inglesa que acontecem na cidade ou em seu entorno;

- organização de grupos de discussão dos docentes em redes sociais para oportunizar a prática da língua inglesa.

(ii) A linha de ação aperfeiçoamento didático-pedagógico:

Esta linha de ação tem como foco a ação didático-pedagógica da formação do professor e foi elaborada com base na confluência de três campos de saberes: (a) as necessidades manifestadas pelos docentes; (b) as prescrições e orientações diretivas dos documentos oficiais que versam sobre a formação contínua no município de Vitória; e (c) os direcionamentos apontados pela literatura da área de formação de professores de língua estrangeira. Assim orientado, o roteiro sugestivo de ações formativas está estruturado para acontecer em oito encontros ao longo do ano letivo, em conformidade com o número máximo de reuniões prescrito em documento diretivo municipal (VITÓRIA, 2007) para as formações por área de conhecimento. Ainda, são sugeridas atividades de extensão para serem realizadas após os encontros previstos. O roteiro sugestivo traz, ainda, ideias adicionais que visam estimular os professores de Língua Inglesa em seu aperfeiçoamento. As oito ações formativas sugeridas encontram-se a seguir especificadas.

\section{Ação formativa 1: A Formação e o ensino de Inglês: entendimentos, pressupostos e responsabilidades}

A escolha desta temática fundamentou-se em dois aspectos: a falta de alinhamento entre as visões da gestão e do professorado quanto às concepções que essas partes têm em relação ao processo formativo oferecido pela PMV e a falta de clareza demonstrada pelos professores quanto a seu entendimento sobre as habilidades linguísticas (reading, writing, speaking e listening) e formas de trabalhá-las. Esta ação formativa objetiva a plena exposição, ao grupo de professores, do entendimento que a PMV tem sobre a formação contínua que oferece, seus documentos reguladores e as expectativas da instituição a respeito das reuniões formativas e seus participantes. Ainda, esta ação formativa tem o objetivo de esclarecer plenamente o que a PMV espera do ensino da Língua Inglesa e dar oportunidade para os professores expressarem suas opiniões sobre o que lhes será oferecido. Assim, a partir da exposição das partes, esta primeira ação almeja ombrear o pensamento dos participantes às intenções institucionais, pois a clareza de posicionamentos é salutar nessa relação.

Atividades:

- apresentação, feita pela gerência da GFDE, sobre o que é preconizado nas Diretrizes Curriculares para o Ensino Fundamental (VITÓRIA, 2004a), focalizando e elucidando o papel do professor crítico-reflexivo enquanto agente no processo de ensinoaprendizagem de seus alunos;

- apresentação e discussão das Diretrizes Curriculares para o Ensino de Língua Estrangeira (VITÓRIA, 2004b), focalizando a reflexão quanto ao papel do professorpesquisador, as concepções de língua e linguagem e os reflexos dessas concepções na prática pedagógica do ensino-aprendizagem de Inglês;

- esclarecimento dos eixos temáticos - conhecimento de mundo, conhecimento sistêmico, conhecimento textual e conhecimento atitudinal (VITÓRIA, 2004b) - a serem 
desenvolvidos nas aulas de Língua Inglesa, os quais devem abarcar os conteúdos trabalhados;

- disponibilização, pela GFDE, dos documentos ora tratados para acesso dos professores;

- explanação, feita por especialista em ensino de Língua Inglesa, sobre o entendimento do que sejam as habilidades linguísticas e formas de promover seu desenvolvimento dentro do que é orientado pelas Diretrizes municipais;

- exemplificação farta de ilustração de atividades realizadas para o desenvolvimento das habilidades;

- discussão a respeito da pertinência e adequabilidade quanto à promoção do desenvolvimento de tais habilidades nas salas de aula;

- divisão dos professores em quatro grupos, um para cada habilidade linguística, para levantamento de possíveis maneiras de se desenvolver a habilidade e posterior compartilhamento dos levantamentos entre os grupos;

- atividade de extensão 1: aplicação de maneiras aprendidas para se trabalhar com duas das habilidades e posterior relato sobre sua experiência para os colegas e especialista palestrante via canal virtual de comunicação 9 ;

- atividade de extensão 2: abastecimento do banco virtual ${ }^{10}$ com contribuições teóricas e práticas pertinentes às temáticas tratadas nesta primeira ação formativa.

\section{Ação formativa 2: Disciplina e interesse do alunado}

A falta de disciplina e de interesse do alunado foi a temática mais mencionada na análise de necessidades realizada com os docentes. Ao serem questionados sobre a natureza das melhorias que precisavam ser feitas para que seu desempenho fosse melhor em sala de aula, $43,4 \%$ dos participantes indicaram esse tema como o primordial. Considerando que a ausência desses aspectos pode comprometer o processo educativo, é necessário que se examine essa questão não com o objetivo de apontar culpados, e sim com o objetivo de identificar aspectos comuns a esse problema, para que se possa compreendê-lo e traçar estratégias para minimizá-lo. Dessa forma, esta temática, a mais mencionada na análise de necessidades realizada com os docentes, tem como objetivo ouvir os professores acerca dos episódios de indisciplina e desinteresse em suas salas de aula. É importante conhecer como esses episódios acontecem para não somente contestar suas ocorrências, mas sim buscar possíveis soluções.

Atividades:

- apresentação de especialista em assuntos sobre adolescência para orientações quanto a maneiras de se lidar com esse público, tanto no aspecto disciplinar quanto motivacional;

- apresentação e discussão de excertos de filmes, vídeos ou trabalhos científicos nos quais configuram-se situações de indisciplina, desrespeito, rebeldia, desobediência e desinteresse pela escola;

- depoimentos sobre situações de indisciplina e desinteresse de alunos vivenciadas pelos professores e as medidas por eles adotadas;

- levantamento de ações passíveis de amenizar episódios de indisciplina, tanto por parte do sistema educacional quanto por parte de cada professor em suas respectivas unidades escolares;

\footnotetext{
9 O canal virtual de comunicação é resultante da criação de um grupo fechado, lista de discussão ou blog entre os docentes da língua inglesa da PMV com o intuito de propiciar um contato mais direto entre eles e convidados (como os palestrantes das ações formativas).

${ }^{10} \mathrm{O}$ banco de dados virtual é um espaço para compartilhamento de ideias, dúvidas, sugestões e atividades entre os professores de Inglês da PMV, participantes ou não das ações formativas.
} 
- levantamento de ações e estratégias motivacionais para despertar o interesse do alunado para o estudo da Língua Inglesa;

- atividade de extensão 1: por meio de pesquisas, aprofundar os assuntos discutidos para posterior abastecimento do banco virtual, com contribuições teóricas e práticas pertinentes à temática;

- atividade de extensão 2: proposta de discussão sobre medidas coletivas para lidar com a indisciplina e o desinteresse dos alunos em seus espaços escolares.

\section{Ação Formativa 3: Metodologias e técnicas de ensino}

Esta temática foi diretamente indicada pelos professores como um assunto a ser contemplado nas Formações, quando lhes foi perguntado que assuntos gostariam que fossem abordados nas reuniões. De forma não pontual, ela também foi apontada quando os professores se manifestaram desfavoravelmente em relação à qualidade do processo formativo oferecido pela PMV e quando declararam suas necessidades para um melhor desempenho nas aulas e necessidades para lidar com os diferentes públicos. Dessa forma, esta ação formativa tem o objetivo de chamar a atenção dos participantes para dois aspectos das Diretrizes Curriculares para o Ensino de Línguas Estrangeiras (VITÓRIA, 2004b): a visão de linguagem e a metodologia para o ensino de línguas. Em relação à metodologia, como esse documento não explicita qual(is) deva(m) ser contemplada(s), esta ação formativa sugere que se faça uma revisão das metodologias, abordagens e técnicas de ensino condizentes com os propósitos da educação linguística dessas Diretrizes.

Dois são os pré-requisitos desejáveis para esta ação formativa: (1) os professores participantes devem trazer os livros didáticos com os quais trabalham e (2) o ambiente em que for realizada a ação formativa deve estar equipado com filmadora e tela para apresentação das filmagens feitas.

Atividades:

- explanação, feita por especialista da área, quanto às teorias de linguagem, enfatizando a concepção bakthiniana referida nas Diretrizes, que concebe a língua como instrumento de interação social e não apenas como comunicação;

- revisão, feita por especialista da área, das teorias e técnicas de ensino;

- formação de grupos para escolha de assuntos nos respectivos livros didáticos de diferentes anos letivos, para levantamento das técnicas possíveis de serem aplicadas em suas salas de aula;

- dramatização videogravada dos professores de como desenvolveriam os assuntos escolhidos nos livros didáticos com seus alunos em sala;

- apreciação do especialista, dos participantes e do próprio professor sobre as videogravações;

- atividade de extensão 1: aplicação pelos professores em suas turmas, de técnicas de ensino diferentes das anteriormente desenvolvidas;

- atividade de extensão 2: relato e discussão das atividades realizadas, ilustrados com o retorno que tiveram de seus alunos, por meio de um canal virtual de comunicação;

- atividade de extensão 3: abastecimento do banco virtual com contribuições teóricas e práticas pertinentes à temática.

Ação formativa 4: Pesquisa-ação e sua possível contribuição ao ensino-aprendizagem de Língua Inglesa 
A Política de Formação Continuada para os Profissionais da Educação do Sistema Municipal de Ensino de Vitoria (VITÓRIA, 2007) menciona a pesquisa-ação como uma possível prática pedagógica a ser desenvolvida por seus profissionais. A pesquisa-ação é apropriada para o ensino de línguas, é de fácil execução e traz resultados visíveis (BURNS, 1999; WALLACE, 1998). Constitui uma maneira de se estudar o ambiente de trabalho, buscando respostas para situações que dificultam o bom andamento da aula. Sua prática pode ser entendida como uma preparação do professor para o exercício seguro e autônomo de suas atividades, sem a dependência irrefutável de teorias a ele impostas. Além disso, o professor-pesquisador constitui um paradigma das Diretrizes municipais (VITÓRIA, 2004b). Assim, embora os professores não tenham mencionado a pesquisa-ação como um assunto a ser abordado nas Formações, a abordagem dessa temática se faz pertinente.

Atividades:

- apresentação do conceito, características e pertinência da pesquisa-ação, por profissional familiarizado com esse tipo de pesquisa;

- ilustração e discussão de situações em que a pesquisa-ação foi desenvolvida;

- formação de grupos para análise de eventos em que a pesquisa-ação foi desenvolvida;

- apresentação dos eventos analisados pelos grupos, com foco em aspectos como: opinião pessoal e discordância ou concordância em relação às opções dos protagonistas dos eventos, em relação às atitudes dos participantes, se eventualmente estivessem no papel dos protagonistas dos eventos, e em relação às suas vivências, se já as tiveram, em situações similares;

- enumeração, feita individualmente pelos participantes, das dificuldades enfrentadas com as turmas com as quais trabalham;

- agrupamento dos professores e eleição de problemas a serem investigados, designando, preferencialmente, um professor para cada situação-problema;

- elaboração, com base nos pressupostos da pesquisa-ação, das fases de investigação a serem desenvolvidas em uma sala de aula determinada;

- atividade de extensão 1: execução e registro da pesquisa-ação eleita por cada professor em uma de suas salas de aula;

- atividade de extensão 2: reflexão acerca da pesquisa-ação realizada, com um par da área da Educação;

- atividade de extensão 3: relato e discussão das pesquisas desenvolvidas em um próximo encontro presencial ou por meio de comunicação eletrônica, preferencialmente com uso de imagens em vídeo;

- atividade de extensão 4: registro de sua experiência no banco de dados virtual;

- atividade de extensão 5: compartilhamento da experiência da pesquisa-ação com colegas de suas unidades de ensino para consideração da viabilização do exercício dessa prática também para outras disciplinas.

\section{Ação formativa 5: Exploração e adequação do material didático}

Os docentes participantes da pesquisa manifestaram variadas reclamações a respeito do material didático utilizado nas aulas de Língua Inglesa, como a carência de material didático para o EF I e para a EJA e o questionamento acerca da pertinência dos livros didáticos adotados para o EF II. Vários desses docentes não acolhem o material didático adotado e a maioria informa que precisa realizar adaptações nas atividades. Por tais razões, os objetivos desta quinta ação formativa são oportunizar o compartilhamento de materiais didáticos entre os diferentes segmentos e conscientizar os professores de que é possível trabalhar com o material disponível no momento. Isso porque é pressuposto que a adequação do material didático para os propósitos e contextos aos quais se destina faz parte do ofício de professor. 
Como pré-requisito, é desejável que os professores tragam os livros didáticos e as atividades com os quais trabalham.

Atividades:

- explanação, por especialista, sobre elaboração e adequação de material didático;

- agrupamento dos professores de acordo com os anos letivos com os quais trabalham, para levantamento das tarefas que eles consideram mais difíceis de serem desenvolvidas com seus alunos;

- apresentação dessas considerações para os demais colegas para comparação e contraste;

- seleção das atividades consideradas difíceis para (re)aplicação em suas salas;

- atividade de extensão 1: (re)aplicação das atividades escolhidas pelos professores;

- atividade de extensão 2: compartilhamento das experiências em um próximo encontro presencial ou por meio de comunicação eletrônica, preferencialmente com uso de imagens em vídeo;

- atividade de extensão 3: abastecimento do banco de dados com as atividades aplicadas.

\section{Ação formativa 6: Produção e execução de atividades listening e speaking}

As habilidades linguísticas listening e speaking são as habilidades em que os professores mais manifestaram sentir dificuldades para preparar atividades que as contemplassem prioritariamente e também como as atividades mais desafiadoras para serem desenvolvidas em sala de aula. Além disso, ao serem perguntados em que habilidades linguísticas gostariam de ter mais proficiência, expressando seus desejos formativos, os docentes participantes as mencionaram como as principais.Como não cabe a este roteiro sugestivo ir além das linhas de ação anteriormente explicitadas, o aperfeiçoamento linguístico e o aperfeiçoamento didáticopedagógico, esta ação formativa tem o objetivo de esclarecer o professor acerca de seu papel como agente social, ao qual subjaz a concepção de preparar seu aluno para agir no mundo. Como orientado pelas Diretrizes Curriculares para o Ensino de Língua Estrangeira (VITÓRIA, 2004b), para que o objetivo de se preparar o aprendiz para agir em sua sociedade seja alcançado, é preciso fazê-lo capaz de se comunicar utilizando a língua inglesa em suas quatro habilidades. Contudo, esta ação formativa focaliza, prioritariamente, as habilidades consideradas as mais difíceis pelos professores.

Dois são os pré-requisitos desejáveis para esta ação formativa: (1) os professores devem trazer os livros didáticos com os quais trabalham e as atividades complementares de listening e speaking que utilizam ou gostariam de utilizar com seus alunos; e (2) o ambiente em que for realizada a ação formativa deve estar equipado com aparelhos de áudio, vídeo e reprodutor de DVD.

Atividades:

- apresentação, por profissional experiente, de ideias de aproveitamento, utilização e adaptação de atividades;

- agrupamento dos professores, de acordo com os anos letivos com os quais trabalham, para seleção de atividades de listening e speaking das diferentes temáticas desenvolvidas em seus conteúdos programáticos;

- apresentação de como essas atividades são trabalhadas;

- contribuição dos demais colegas participantes para com as apresentações, com base em suas respectivas bagagens pedagógicas;

- seleção das atividades apresentadas nesta sexta ação formativa nunca utilizadas pelos professores para aplicação em suas aulas; 
- atividade de extensão 1: aplicação das atividades selecionadas em suas salas, com ou sem adaptações;

- atividade de extensão 2: compartilhamento das experiências referentes à aplicação das atividades em um próximo encontro presencial ou por meio de comunicação eletrônica;

- atividade de extensão 3: abastecimento do banco de dados com as atividades desenvolvidas, podendo os professores, ainda, adicionar suas percepções e indicações para futuro usos dessas atividades.

\section{Ação formativa 7: Inclusão de alunos com necessidades especiais nas aulas de Inglês}

Esta temática foi diretamente indicada pelos professores como um assunto a ser contemplado nas Formações. Isso pode ter sido decorrência do fato de mais da metade dos professores participantes não se considerarem preparados para lidar com esses alunos. Desse modo, esta seção formativa tem como objetivo oferecer aos docentes oportunidades de desenvolvimento e aprofundamento acadêmico, profissional e pessoal sobre a natureza e a complexidade das questões que envolvem o ensino-aprendizagem de pessoas com necessidades especiais, tendo em vista que a escola inclusiva é uma aspiração da Educação brasileira.

Atividades:

- apresentação, feita por especialista, de experiências bem sucedidas sobre o ensino de língua estrangeira para alunos com necessidades especiais de aprendizagem, focalizando, especialmente, as características diferenciadas de aprendizagem desses alunos, em suas diferentes manifestações e comorbidades e a diversidade de opções pedagógicas disponível para o ensino-aprendizagem de língua estrangeira;

- depoimentos de professores em relação a experiências por eles vivenciadas, ou por colegas, com enfoque nos resultados obtidos e na concepção pessoal desses docentes sobre o diferencial para a (não) inclusão desse aluno em suas aulas;

- apresentação, pelo palestrante, de registros de depoimentos de pais desse alunado sobre suas expectativas e opiniões acerca do ensino recebido por seus filhos;

- discussão dos professores quanto aos registros apresentados, manifestando suas opiniões e sugestões para que a inclusão de alunos com necessidades especiais aconteça plenamente;

- exemplificação, por parte dos professores, de atividades e/ou tarefas que já realizaram com seus alunos com necessidades especiais;

- discussão sobre a viabilidade da aplicação das atividades desenvolvidas por colegas, se utilizadas com outros alunos com necessidades especiais;

- atividade de extensão 1: aplicação de atividades inéditas junto a seus alunos de necessidades especiais em seus contextos de ensino;

- atividade de extensão 2: compartilhamento de suas experiências por meio de canal virtual de comunicação ou na próxima ação formativa;

- atividade de extensão 3: abastecimento do banco de dados virtual com seus relatos de experiências.

\section{Ação formativa 8: Uso de novas tecnologias}

Esta temática também foi diretamente indicada pelos professores como um assunto a ser contemplado nas Formações. Tal indicação pode ser decorrente do fato de que a geração atual, especialmente a composta por jovens de classes sociais menos privilegiadas, como a clientela das escolas públicas de Vitória, poderia vislumbrar a escola de forma mais positiva, caso a tecnologia, em especial a internet, estivesse mais presente em seu cotidiano escolar. 
Provavelmente, esses alunos se sentiriam mais atraídos e interessados em realizar atividades que usam aparato tecnológico, tendo em vista que, muitas vezes, não dispõem, em seus lares, de acesso ilimitado a computadores. Assim, o objetivo desta ação formativa é oportunizar aos professores o acesso a variadas fontes de atividades que possam ser praticadas com seus diferentes alunos.

Dois são os pré-requisitos desejáveis para esta ação formativa: (1) os professores devem trazer os livros didáticos com os quais trabalham, as atividades que já desenvolveram com seus alunos nos laboratórios de informática da escola e uma lista de sítios eletrônicos que usam para a elaboração de atividades realizadas no computador; e (2) o ambiente em que for realizada a ação formativa deve estar aparelhado com computadores para uso dos professores.

Atividades:

- apresentação, por especialista na área de tecnologia educacional, de ferramentas tecnológicas que podem ser exploradas pelos professores de Língua Inglesa, tais como o computador, os telefones celulares, os aplicativos e os ambientes virtuais de aprendizagem e comunicação;

- apresentação de sítios eletrônicos utilizados pelos professores;

- manuseio dos aplicativos e sítios eletrônicos indicados pelo palestrante e por colegas;

- seleção de atividades que os professores gostariam de experienciar com seu alunado;

- agrupamento dos professores de acordo com os anos letivos para os quais lecionam para avaliar a qualidade das propostas trazidas em seus livros didáticos;

- levantamento, para os diferentes anos letivos, de sugestões de novas tarefas que façam uso das ferramentas e sítios eletrônicos apresentados;

- discussão acerca da adequabilidade das atividades selecionadas;

- escolha de atividade(s) nunca utilizada(s) antes pelo professor para ser(em) desenvolvida(s) em sala de aula;

- atividade de extensão 1: relato, por meio de comunicação virtual, da experiência realizada;

- atividade de extensão 2: abastecimento do banco de dados com os sítios eletrônicos e as sugestões de ferramentas tecnológicas abordados, bem como as experiências realizadas.

\section{Ideias adicionais para o roteiro sugestivo de ações formativas}

- proposição e encorajamento do uso de canais de comunicação virtual (como blogs ou grupos fechados de discussão) entre os docentes de Língua Inglesa da rede;

- criação de um banco de dados virtual no qual os professores possam solicitar, sugestionar, postar e comentar atividades cotidianas, jogos aplicados, tarefas de reforço ou exercícios avaliativos desenvolvidos com seus alunos, de acordo com o ano escolar e o tema da atividade;

- incentivo à participação dos docentes em cursos de extensão ou em pós-graduação em sua área de conhecimento;

- divulgação e encorajamento do uso de programas presenciais ou on-line interativos, oferecidos por editoras de livros didáticos;

- estímulo para a participação em eventos, nos quais os docentes possam trocar experiências com palestrantes e professores de outras escolas e municípios;

- viabilização de formações específicas para professores de Língua Inglesa que atuam no EF I e na EJA;

- constituição de grupos de estudo para desenvolvimento de tarefas de acordo com o assunto abordado em séries específicas, em especial para o EF I e EJA, tendo em vista que para ambos não há adoção de material didático pela rede de ensino; 
- acompanhamento pedagógico aos professores iniciantes ou em caráter temporário, o qual pode ser efetivado por meio de assessoria pedagógica oferecida pela SEME ou por meio de professores da rede que sejam mais experientes e se voluntariem para auxiliar os novatos;

- estabelecimento de grupos de estudo para criação de atividades avaliativas em consonância com conteúdos desenvolvidos nos diferentes anos escolares;

- fomento para que professores da mesma disciplina que atuam em uma mesma unidade escolar, em turnos diferentes, possam se comunicar melhor, compartilhar seus questionamentos e vivências, por meio de relatos escritos ou fazendo uso de aparato tecnológico;

- melhorias no sistema de comunicação entre a SEME e os professores de Inglês para que as informações sobre assuntos gerais e também os pertinentes à área alcancem efetivamente o professor;

- organização de encontros sociais, como um café à tarde ou um passeio de bicicleta pela cidade, para que os professores tenham chances de estreitar seus laços afetivos.

Acredito que o roteiro sugestivo apresentado comprova que a análise de necessidades é capaz de oferecer subsídios para que um programa de formação contínua cumpra seu papel de atender às reais necessidades de seus participantes. Neste momento, faz-se importante chamar a atenção para o fato de que, embora este roteiro tenha buscado englobar o maior número possível das demandas manifestadas pelos professores, explicitamente ou não, aspectos não foram contemplados, como, por exemplo, questões relacionadas à estrutura física das escolas, ao número excessivo de alunos em sala de aula, ou à inviabilidade de o professor de Inglês contar com uma sala ambiente. Tais demandas, embora explicitamente manifestadas pelos professores, não foram abarcadas, haja vista a natureza deste roteiro, meramente sugestivo, cujo escopo é a formação contínua.

Ações formativas apresentadas no roteiro sugestivo, por serem fiéis ao contexto no qual foram propostas, por contemplarem as necessidades dos professores e por serem condizentes com os documentos oficiais que regem a Educação, ombreiam o pensamento dos participantes às intenções institucionais. Dessa forma, tais ações favorecem a diminuição da resistência entre os posicionamentos das partes envolvidas e oportunizam o cultivar de uma relação salutar. Vale reiterar que a proposta do roteiro, com suas detalhadas ações formativas e sugestões de ideias adicionais, visam simplesmente constituir um banco referencial de ideias de ação, tanto para os gestores, quanto para os professores.

\section{Referências}

ALMEIDA, C. S. de. A formação contínua de professores de língua inglesa da rede municipal pública de ensino de Vitória, ES, à luz da análise de necessidades. 2014. $228 \mathrm{f}$. Tese (Doutorado em Linguística Aplicada e Estudos da Linguagem) - Pontifícia Universidade Católica de São Paulo, São Paulo, 2014.

BURNS, A. Collaborative action research for English language teachers. Cambridge: Cambridge University Press, 1999.

GALINDO, C. J.; INFORSATO, E. C. Manifestações de necessidades de formação continuada por professores do $1^{\circ}$ ciclo do ensino fundamental. Dialogia (UNINOVE), [S.1.], v. 7, p. 63-78, 2008 . 
KUMARAVADIVELU, B. Language teacher education for a global society: a modular model for knowing, analyzing, recognizing, doing, and seeing. New York: Routledge, 2011.

OLIVEIRA, R. S. Por uma prática reflexiva no ensino de línguas estrangeiras: saberes e diálogos. 2010. 367 f. Tese (Doutorado em Letras) - Faculdade de Filosofia, Letras e Ciências Humanas, Universidade de São Paulo, 2010.

RODRIGUES, A.; ESTEVES, M. A análise de necessidades na formação de professores. Porto: Porto Editora, 1993.

SANTANA, A. C. M. As percepções sobre as necessidades de formação continuada dos gestores e dos professores de língua portuguesa e inglesa: algumas reflexões. 2010. $203 \mathrm{f}$. Tese (Doutorado em Educação Escolar) - Faculdade de Ciências e Letras, Campus de Araraquara, Universidade Estadual Paulista, São Paulo, 2010.

VILLANI, F. L. As crenças do professor e suas repercussões na sala de aula de língua inglesa na Escola Pública: o Olimpo está mais próximo do que parece... 2010. $168 \mathrm{fls}$. Tese (Pós-doutorado em Linguística Aplicada e Estudos da Linguagem) - Pontifícia Universidade Católica de São Paulo, São Paulo, 2010.

VITÓRIA. Decreto 12.666. Estabelece a forma de organização e regulamenta o funcionamento das unidades administrativas da Secretaria de Educação. Vitória, 2006a. Disponível em: <http://sistemas.vitoria.es.gov.br/webleis/Arquivos/2006/D12666.PDF>. Acesso em: set. 2012.

Lei Complementar 3. Institui e regulamenta o Sistema de Avaliação Especial de Desempenho para Servidores em Estágio Probatório. Vitória, 2008. Disponível em: < http://sistemas.vitoria.es.gov.br/webleis/Arquivos/2008/LC3.PDF>. Acesso em: abr. 2014.

Secretaria Municipal de Educação. Documentos Norteadores do Ensino Fundamental. Diretrizes curriculares para o ensino fundamental. Vitória, 2004a. Disponível em: $<$ http://www.vitoria.es.gov.br/arquivos/20100218_ens_fund_dir_curriculares.pdf $>$. Acesso em: mar. 2013.

Secretaria Municipal de Educação. Documentos Norteadores do Ensino Fundamental. Diretrizes curriculares para o ensino fundamental: língua estrangeira - Inglês. Vitória, 2004b. Disponível em: <http://www.vitoria.es.gov.br/arquivos/20100218_ens_fund_dir_ingles.pdf>.Acesso em: mar. 2013.

Secretaria Municipal de Educação. Subsecretaria político-pedagógico. Gerência de formação e desenvolvimento em educação. Política de formação continuada para os profissionais da educação no sistema municipal de ensino de Vitória. Vitória, 2007. Disponível em: <http://www.vitoria.es.gov.br/seme.php?pagina=formacoes>. Acesso em: mar. 2013.

WALLACE, M. J. Action research for language teachers. Cambridge: Cambridge University Press, 1998. 
